\title{
O Estado da Arte da Pesquisa em Educação Ambiental no Brasil ${ }^{1}$
}

\author{
Marcos Reigota \\ Programa de Mestrado em Educação \\ Universidade de Sorocaba
}

Resumo: Este artigo é o resultado de uma pesquisa que procura analisar a produção acadêmica brasileira em educação ambiental no período compreendido de 1984 a 2002. As teses e dissertações defendidas nos departamentos de Educação, Ecologia, Saúde Pública, Educação Ambiental, entre outros, são a principal fonte de consulta. A pesquisa revela a existência de pelo menos uma tese de livre-docência, 40 de doutorado e 246 dissertações abrangendo diversos temas ambientais, concepções pedagógicas e políticas. Os principais temas abordados são: relações entre natureza e cultura, crise ambiental urbana e ecossistemas específicos. Nos aspectos pedagógicos, a educação ambiental é considerada um processo que pode ocorrer em todos os espaços de aprendizagem e estar presente no currículo de todas as disciplinas. $\mathrm{O}$ estímulo ao processo de participação social visando a construção de uma sociedade democrática e sustentável é o aspecto político mais enfatizado. $\mathrm{O}$ artigo sugere que uma ampla e maior compreensão da educação ambiental nas universidades, agências de fomento e na definição de políticas públicas será possível por meio da difusão dessa produção.

Palavras-chave: Educação Ambiental. Linhas de Pesquisa. Políticas Públicas. Processos Pedagógicos.

1 Texto elaborado com base na Pesquisa "Fundamentos políticos e pedagógicos da educação ambiental brasileira: análise a partir da produção universitária". Financiado pela Universidade de Sorocaba. 
Abstract: The present study makes use of the results of a research of broader scope. It aims to describe the production of environmental education in Brazil and others countries by Brazilians during the period 1984-2002. Doctoral theses and Master dissertations are the source of investigation, particularly those written in education, ecology, public health and environmental education post-graduate departments. The study reveals the existence of at least 1 Full-professor thesis, 40 Dosctoral theses and 246 Master dissertations, with many environmental topics, pedagogical concepts and processes and political emphasis. Major environmental topics include the relationship between nature and culture, the environmental crisis on metropolis and specific ecosystems. Regarding the pedagogical field, it is pointed out the idea that environmental education is a process which may be included in every educational place and into every subject curriculum. The fomentation of participatory processes oriented towards the construction of a democratic and sustainable society is the most emphasized political aspect. This study concludes by affirming that a new understanding about environmental education in Brazilian universities and in governamental and private research agencies provides a progress in the field and in the public policies related to environment, education and research.

Keywords: Environmental Education. Research Policies. Public Policies. Pedagogical Processes.

Desde 1984, a educação ambiental se tornou tema de dissertações, sendo a primeira tese de doutorado defendida em 1989 na Universidade de São Paulo (CARVALHO, 1989). A partir da segunda metade dos anos 90, concretizou-se a institucionalização da educação ambiental em diferentes departamentos de pós-graduação.

A informação sobre essa produção começou a circular, aumentando o interesse pela sua fundamentação política e pedagógica. Políticas públicas relacionadas com a educação ambiental foram elaboradas, colocando em evidência a urgência de pesquisas.

Levantamentos não sistematizados, pessoais e institucionais foram realizados procurando dar conta dessa produção ${ }^{2}$. Um

2 Agradeço a colaboração dos/as colegas Arion de Castro Kurtz dos Santos, Luis Afonso Vaz de Figueiredo, Hedy Silva Ramos de Vasconcelos, Luiz Marcelo de Carvalho 
primeiro projeto de pesquisa, com o objetivo de elaboração de um banco de dados financiado pelo $\mathrm{CNPq}$, foi feito pela professora Hedy Silva Ramos de Vasconcelos, do Programa de Pós-graduação em Educação da Pontifícia Universidade Católica do Rio de Janeiro.

Em outros países como Austrália, Canadá e Inglaterra, a pesquisa em educação ambiental vem sendo discutida e analisada apontando novos enfoques teóricos, pedagógicos, políticos e socioambientais (GOUCH, 2000; SAUVÉ, 2000).

Considerando a importância planetária da temática ambiental brasileira e o acúmulo e tradição em pesquisa educacional no país, uma pesquisa como esta estava para ser feita.

Dessa forma, os dados e interpretação dos mesmos aqui apresentados dialogam com outros estudos que procuram analisar a produção sobre temas educacionais específicos (MENDES, 2000 e MEGID, 1998) e, particularmente, com a temática ambiental (DRUMMOND, 1998; SCHROEDER, 1998; GARNIER, 2000; GOUGH, 2000; GOYA, 2000; NOVICKI, 2001; REIGOTA, 1999; ROCHA, 2002; SAUVÉ, 2000; SEVERINO, 2001; TRAJBER; MANZOCHI, 1996, VASCONCELOS, 1999).

Tendo observado esse movimento desde o seu início (REIGOTA, 2001) e a difusão que a educação ambiental teve nas últimas décadas no espaço privilegiado das universidades, era o momento de pesquisá-lo tendo como objetivo colocar em evidência a cartografia dessa produção e as suas principais características pedagógicas e políticas.

Ao optarmos por uma análise da produção científica, ou seja, pelas teses e dissertações, deixamos de lado os seus produtos anteriores e posteriores como artigos e livros para traçar o "Estado da Arte" de uma área de conhecimento que define o seu campo entre outras áreas específicas da educação.

As noções de "Estado da Arte" que adotamos apóiam-se nas de Mary Jane Paris Spink no seu estudo sobre a Teoria das Representações Sociais (SPINK, 1996), no qual a autora define o Estado da Arte como "uma exposição sobre o nível de conhecimento e desenvolvimento de um campo ou questão" (SPINK, 1996, p. 167).

Em resumo, nossa pesquisa tem a característica essencialmente exploratória, com base em documentos de domínio

e Mônica Arruda, que disponibilizaram seus dados, e os pareceristas deste artigo, pelas observações e sugestões. 
público, "da literatura científica relativa ao objeto de estudo e cujo objetivo é a exploração da literatura procurando elaborar uma problemática teórica” (DE KETELE; ROEGIERS, 1996, p. 33).

Nosso trabalho procura enfocar os aspectos pedagógicos e políticos da educação ambiental presentes nas teses e dissertações defendidas em universidades brasileiras ou por pesquisadores/as brasileiros/as no exterior.

Para obter os dados necessários, anunciamos o projeto nas redes e entre colegas da área. Consultamos bancos de dados, como o Prossiga do CNPq, catálogos de programas de pós-graduação, bibliografia de artigos, livros, documentos diversos, além das teses e dissertações de cujas bancas participamos.

De novembro de 2000 a novembro de 2002, foram levantadas 1 tese de livre-docência, 40 teses e 246 dissertações. ${ }^{3}$

Esse levantamento, provavelmente, não contempla todas as teses e dissertações defendidas desde 1984. Apesar da busca insistente junto aos pesquisadores/as, dados sobre alguns trabalhos não foram localizados em tempo hábil, para que fossem incluídos e analisados.

Essa dificuldade poderá ser sanada, desde que se estabeleça um banco de dados específico para a área.

A maior dificuldade que encontramos não foi a de localização das informações e a precisão quantitativa, mas sim definir o que é um trabalho de pesquisa em educação ambiental.

No levantamento inicial, e em diálogos com colegas da área, foi comum, quando solicitava os dados de suas pesquisas, ouvir a seguinte frase: "A minha dissertação/tese não é de educação ambiental".

Diante de nossa insistência, obtivemos os dados solicitados. Foram consideradas como sendo teses e dissertações de educação ambiental aquelas que:

1. Trazem no título: educação ambiental e palavras-chave: meio ambiente, ensino, práticas pedagógicas ou similares.

2. Abordam temáticas ambientais defendidas em Programas de Pós-graduação em Educação.

\footnotetext{
3 Até o momento (abril de 2005), nosso levantamento registra 1 tese de livre-docência, 48 teses e 349 dissertações.
} 
3. Abordam temáticas educacionais e ambientais defendidas em Programas de Pós-graduação como Saúde Pública, Ecologia, Psicologia, Sociologia, etc.

4. Os/as pesquisadores/as são conhecidos/as publicamente como educadores/as ambientais, embora os títulos de seus trabalhos universitários não explicitem necessariamente suas relações com a educação ambiental.

5. Os/as pesquisadores/as não explicitam nos títulos dos seus trabalhos nenhuma relação com a educação ambiental, mas, quando indagados por nós, identificam sua pesquisa como sendo de educação ambiental.

Exemplos:

Categoria 1 - Teses e dissertações que trazem no título as palavras-chave: educação ambiental, meio ambiente, ensino, práticas pedagógicas ou similares. Para a caracterização dessa categoria, foram utilizadas como exemplo as teses de Barcelos (2001) e Fracalanza (1992), Matsushima (1992) e a dissertação de Goya (2000).

Categoria 2 - Teses e dissertações que abordam temáticas ambientais defendidas em Programas de Pós-graduação em Educação. Como exemplo para a caracterização dessa categoria, foram utilizadas teses e dissertações que abordam temas como gênero e ocupação do espaço (BERGMANN, 1996), o ambiente das comunidades de imigrantes (BRAUM, 1999), a agroecologia (CURVELO, 1998), manifestações dos povos da floresta (SANTOS, 2001) e a obra de Hans Jonas (ZANCANARO, 1999).

Categoria 3 - Teses e dissertações que abordam temáticas educacionais e ambientais defendidas em Programas de Pósgraduação como Saúde Pública, Ecologia, Psicologia, Multidisciplinares, etc. Para exemplificar essa categoria, foram utilizadas as teses e dissertações que analisam temas como: interdisciplinaridade e meio ambiente (DIAZ, 2001), noções de espaço (HIGUCHI, 1999), formação e/ou adestramento ambiental (POMPÉIA, 1995, NEVES, 1993) e discursos das pesquisas ambientais (SERRÃO, 1995).

Categoria 4 - Teses e dissertações cujos pesquisadores/as são conhecidos publicamente como educadores/as ambientais, embora 
os títulos de seus trabalhos universitários não explicitem necessariamente suas relações com a educação ambiental. Essa categoria foi explicitada levando-se em consideração o reconhecimento público de pesquisadores/as entre os profissionais da educação ambiental.

Categoria 5 - Teses e dissertações em que os/as pesquisadores/as não explicitam nos títulos dos seus trabalhos nenhuma relação com a educação ambiental, mas, quando indagados por nós, identificam sua pesquisa como sendo de educação ambiental. Essa categoria está caracterizada pelas dissertações de: Felippe (2002), Goldgrub (1998), Portilho (1997), Rechineli (2000) e Souza (2002).

\section{Rediscutindo as categorias}

Entre as cinco categorias, a primeira é a que, evidentemente, oferece menos riscos de classificação, pois são inúmeras as teses e dissertações que trazem no título as palavraschave educação ambiental, meio ambiente, ensino, práticas pedagógicas ou similares. As primeiras dissertações, defendidas em 1984, trazem no título essa identificação. São elas a de Gomes (1984) e a de Klein (1984).

A segunda categoria, "Teses e dissertações que abordam temáticas ambientais defendidas em Programas de Pós-graduação em Educação", procura enfatizar como a questão ambiental, sob suas múltiplas possibilidades temáticas, foi sendo pesquisada nos Programas de Pós-graduação em Educação, trazendo nos títulos referências à educação ambiental. Foram defendidas nesses programas, no período analisado, o equivalente a 18 teses e 136 dissertações.

A terceira categoria, "Teses e dissertações que abordam temáticas educacionais e ambientais defendidas em Programas de Pós-graduação em Saúde Pública, Ecologia, Psicologia, Multidisciplinares, etc.", procura relacionar a temática ambiental com as questões educacionais e foi pesquisada em diferentes programas de pós-graduação.

Aqui vale destacar a produção do Programa de Pósgraduação em Saúde Pública da Universidade de São Paulo, onde foi defendida em 2000 a primeira tese de livre-docência, com o título "Educação em saúde e educação ambiental: estratégias de 
construção da escola promotora da saúde", pela professora Maria Cecília Focesi Pelicioni.

Nesse programa, foram também defendidas 6 teses e 9 dissertações.

O Programa de Pós-graduação em Educação Ambiental da Fundação Universidade Rio Grande, pela sua especificidade, é o que tem contribuído com maior quantidade de dissertações (41 até o final do levantamento), apresentando ampla e profícua variedade temática.

A quarta categoria, "Teses e dissertações cujos pesquisadores/as são reconhecidos/as publicamente como educadores/as ambientais, embora os títulos de seus trabalhos universitários não explicitem necessariamente suas relações com a educação ambiental", enfatiza trabalhos realizados por pesquisadores/as que ficaram conhecidos na área por suas publicações sobre educação em editoras comerciais e/ou universitárias, entre eles, Genebaldo Dias, Fernando Noal, Marta Catunda. Nessa categoria, também se incluem pesquisadores/as e professores/as como Maria Cecília Focesi Pelicioni e Roberto Leher.

Genebaldo Dias é autor de "Educação ambiental: princípios e práticas", que em 2002 se encontrava na $\sigma^{a}$ edição. Fernando Noal organizou, juntamente com Valdo Barcelos e Marcos Reigota, "Tendências da Educação Ambiental", cuja 2a edição foi publicada em 2001.

Marta Catunda tem um trabalho específico, no qual procura desenvolver o paradigma estético (GUATTARI, 1991), aliando a sua produção teórica a atividades artísticas e musicais, em parceria com a cantora e compositora Tetê Spíndola. O seu livro "Canto do céu aberto e de mata fechada", originado de sua dissertação defendida na Universidade de São Paulo, publicado pela editora da Universidade Federal do Mato Grosso, é um dos mais originais da área.

Maria Cecília Focesi Pelicioni é professora da Faculdade de Saúde Pública, da Universidade de São Paulo, tendo aí defendido em 1989 a sua dissertação de mestrado em 1995, a tese de doutorado e, em 2000, a tese de livre-docência. Participa do Programa de Especialização em Educação Ambiental da Universidade de São Paulo, tem vários artigos publicados, organizou livros e orientou várias teses e dissertações sobre o tema.

Sua relação com a educação ambiental iniciou-se com Denise Del Rey, que foi professora da Universidade de São Paulo 
antes de se transferir para o Rio de Janeiro. Denise Del Rey participou das primeiras reuniões da UNESCO na América Latina que antecederam a conhecida Reunião de Tbilissi de 1977, na qual foram definidos os princípios da educação ambiental (DIAS, 2002).

$\mathrm{Na}$ Universidade Federal do Rio de Janeiro, ela funda o GEEA, Grupo de Estudos em Educação Ambiental, que contava com a participação de Hedy Silva Ramos de Vasconcelos e a de, entre outros, Carlos Frederico Loureiro, Erivaldo Pedrosa, Maria de Lourdes Spazziani, Roberto Leher e Ronaldo de Souza Castro. Todos os nomes citados defenderam teses e dissertações, tornando-se referências na área.

Roberto Leher teve papel destacado nos eventos e seminários do GEEA. Ficou nacionalmente conhecido quando foi diretor do ANDES, Sindicato Nacional dos Docentes das Instituições de Ensino Superior, e liderou uma das mais longas greves de professores em 2001.

Pela sua militância, sofreu perseguições na Universidade Federal do Rio de Janeiro, transferindo-se para a Universidade Estadual do Rio de Janeiro, onde desenvolve pesquisas sobre políticas públicas.

O título de sua tese, "Da ideologia do desenvolvimento à ideologia da globalização como estratégia do Banco Mundial para 'alívio' da pobreza", defendida na Faculdade de Educação da Universidade de São Paulo, em 1998, não apresenta indícios de sua trajetória e reflexões sobre a educação ambiental. Mas tal afirmativa não se sustenta a partir de uma análise do seu conteúdo, razão pela qual foi aqui incluída.

A quinta e última categoria está relacionada com os contatos pessoais que tivemos com os/as pesquisadores/as. Em conversas, encontros em seminários, cursos, bancas e troca de emails, questionamos se o/a pesquisador/a considerava seu trabalho como sendo de educação ambiental. Em caso afirmativo, era incluído no levantamento.

\section{O que dizem os números:}

Numa primeira análise, pode se considerar extremamente importante (embora não suficiente) que, em 18 anos, foram produzidos tantos trabalhos sobre educação ambiental.

Se nos anos 80 a produção foi quantitativamente mínima, com sete dissertações e uma tese, ela tem, no entanto, o mérito histórico de iniciar uma temática nos meios universitários. 
Tabela I - Produção nos anos 80

\begin{tabular}{|c|c|c|}
\hline ANO DE DEFESA & MESTRADO & DOUTORADO \\
\hline 1984 & 2 & - \\
\hline 1987 & 1 & - \\
\hline 1988 & 1 & - \\
\hline 1989 & 3 & $\mathbf{1}$ \\
\hline TOTAL & $\mathbf{7}$ & \\
\hline
\end{tabular}

Nos anos posteriores, o aumento foi significativo, como nos mostram as tabelas II e III.

Tabela II - Produção nos anos 90

\begin{tabular}{|c|c|c|c|}
\hline $\begin{array}{c}\text { ANO DE } \\
\text { DEFESA }\end{array}$ & MESTRADO & DOUTORADO & $\begin{array}{c}\text { LIVRE- } \\
\text { DOCENCIA }\end{array}$ \\
\hline 1990 & 3 & 1 & - \\
\hline 1991 & 5 & - & - \\
\hline 1992 & 8 & 2 & - \\
\hline 1993 & 10 & 1 & - \\
\hline 1994 & 11 & 1 & - \\
\hline 1995 & 26 & 3 & - \\
\hline 1996 & 14 & - & - \\
\hline 1997 & 23 & 3 & - \\
\hline 1998 & 29 & 7 & - \\
\hline 1999 & 30 & 6 & - \\
\hline TOTAL & $\mathbf{1 5 9}$ & $\mathbf{2 4}$ & - \\
\hline
\end{tabular}

Tabela III - Produção nos primeiros anos do século XXI

\begin{tabular}{|c|c|c|c|}
\hline $\begin{array}{c}\text { ANO DE } \\
\text { DEFESA }\end{array}$ & MESTRADO & DOUTORADO & $\begin{array}{c}\text { LIVRE- } \\
\text { DOCÊNCIA }\end{array}$ \\
\hline 2000 & 49 & 5 & 1 \\
\hline 2001 & 20 & 9 & - \\
\hline 2002 & 11 & 1 & - \\
\hline TOTAL & $\mathbf{8 0}$ & $\mathbf{1 5}$ & $\mathbf{1}$ \\
\hline
\end{tabular}




\section{Cartografia}

As universidades públicas, com mestrado e doutorado, são as que mais contribuíram para a expansão da produção na área, destacando-se a Universidade de São Paulo, Universidade Estadual de Campinas, Universidade Estadual Paulista, Universidade Federal do Rio de Janeiro e Universidade Federal do Rio Grande do Sul.

Tabela IV - Universidades brasileiras com mestrado e doutorado

\begin{tabular}{|c|c|c|c|}
\hline $\begin{array}{c}\text { Universidade de } \\
\text { São Paulo }\end{array}$ & MESTRADO & DOUTORADO & $\begin{array}{c}\text { LIVRE- } \\
\text { DOCENCIA }\end{array}$ \\
\hline $\begin{array}{c}\text { Universidade } \\
\text { Estadual de } \\
\text { Campinas }\end{array}$ & 26 & 14 & 01 \\
\hline $\begin{array}{c}\text { Universidade } \\
\text { Federal de São } \\
\text { Carlos }\end{array}$ & 06 & 09 & - \\
\hline $\begin{array}{c}\text { Universidade } \\
\text { Federal de Santa } \\
\text { Catarina }\end{array}$ & 02 & 03 & - \\
\hline $\begin{array}{c}\text { Universidade } \\
\text { Estadual Paulista }\end{array}$ & 09 & 02 & - \\
\hline $\begin{array}{c}\text { Universidade } \\
\text { Federal do Paraná }\end{array}$ & 01 & 02 & - \\
\hline $\begin{array}{c}\text { Universidade } \\
\text { Federal do Rio } \\
\text { Grande do Sul }\end{array}$ & 09 & 01 & - \\
\hline $\begin{array}{c}\text { Universidade de } \\
\text { Brasília }\end{array}$ & 04 & 01 & - \\
\hline $\begin{array}{c}\text { Universidade } \\
\text { Federal do Rio de } \\
\text { Janeiro }\end{array}$ & 14 & & - \\
\hline $\begin{array}{c}\text { Universidade } \\
\text { Federal do Mato } \\
\text { Grosso }\end{array}$ & & & \\
\hline $\begin{array}{c}\text { Universidade } \\
\text { Federal Rural do } \\
\text { Rio de Janeiro }\end{array}$ & 05 & 01 & - \\
\hline TOTAL & & & \\
\hline
\end{tabular}


Apenas duas teses foram defendidas no exterior. São elas a de Marcos Reigota, defendida em 1990 na Universidade Católica de Louvain (Bélgica), com o título "Les représentations sociales de L'environnement et les pratiques pédagogiques quotidiennes de professeurs de sciences à São Paulo-Brésil", e a de Maria Ignes Higuchi, defendida em 1999 na Universidade Brunel (Inglaterra), com o título "House, street, bairro and mata: ideas of place in an urban location in Brazil".

Para as dissertações, aumenta consideravelmente o número de universidades e a diversidade de programas de pós-graduação com produção na área, destacando-se o Programa de Pósgraduação em Educação Ambiental da Fundação Universidade Rio Grande, a Pontifícia Universidade Católica do Rio do Janeiro, a Pontifícia Universidade Católica de São Paulo, a Universidade Federal Fluminense, a Universidade de Santa Maria e a Fundação Getúlio Vargas do Rio de Janeiro

Tabela $\mathrm{V}$ - Defesas em programas de mestrado

\begin{tabular}{|c|c|}
\hline UNIVERSIDADES & DISSERTAÇÕES \\
\hline Fundação Universidade Rio Grande & 41 \\
\hline $\begin{array}{c}\text { Pontifícia Universidade Católica do Rio } \\
\text { de Janeiro }\end{array}$ & 16 \\
\hline $\begin{array}{c}\text { Pontifícia Universidade Católica de São } \\
\text { Paulo }\end{array}$ & 09 \\
\hline Universidade Federal Fluminense & 08 \\
\hline Universidade Federal de Santa Maria & 07 \\
\hline $\begin{array}{c}\text { Fundação Getúlio Vargas do Rio de } \\
\text { Janeiro }\end{array}$ & 06 \\
\hline Universidade Federal do Espírito Santo & 06 \\
\hline $\begin{array}{c}\text { Pontifícia Universidade Católica do Rio } \\
\text { Grande do Sul }\end{array}$ & 05 \\
\hline Universidade Metodista de Piracicaba & 04 \\
\hline Universidade Federal da Paraíba & 04 \\
\hline Universidade Estadual do Rio de \\
Janeiro
\end{tabular}




\begin{tabular}{|c|c|}
\hline Universidade Federal de Minas Gerais & 02 \\
\hline Universidade Braz Cubas & 02 \\
\hline Universidade Federal do Pará & 02 \\
\hline Centro Universitário Frasciscano & 02 \\
\hline Universidade Mackenzie & 02 \\
\hline Universidade Guarulhos & 02 \\
\hline Universidade do Vale do Rio dos Sinos & 02 \\
\hline TOTAL & $\mathbf{1 3 5}$ \\
\hline
\end{tabular}

No nosso levantamento, verificamos que pelo menos uma dissertação sobre educação ambiental foi defendida em 16 universidades. São elas: Universidade Federal de Uberlândia, CEFET-PR, UNIMONTE, Universidade Federal do Ceará, Universidade Estadual do Ceará, Universidade Católica de Petrópolis, INPA-Manaus, Universidade Federal da Bahia, Universidade Estácio de Sá, Universidade Estadual da Bahia, Universidade de Ribeirão Preto, Universidade de Santa Cruz do Sul, FUREG-Blumenau, Universidade Federal de Mato Grosso do Sul, Universidade de Passo Fundo e Universidade Regional de Joinville.

No exterior, foram defendidas, entre outras, as dissertações de Gomes (1984), Pádua (1991) e Rocha (1994) .

As dissertações e teses em educação ambiental foram defendidas nos mais diversos programas de pós-graduação, legitimando e expandindo a sua identidade multi, inter e transdisciplinar. Embora se destaque a produção dos Programas de Pós-graduação em Educação, Educação Ambiental, Ecologia, Saúde Pública, Desenvolvimento e Meio Ambiente e Psicologia, outros programas mostram-se aptos para o tema. Entre eles, destacamos os de Comunicações e Artes, Engenharia, Serviço Social, Geografia, assim como os de Tecnologia, Filosofia e Saúde Mental.

Tabela VI - Especificidades dos programas de mestrado e doutorado

\begin{tabular}{|c|c|c|c|}
\hline PROGRAMAS & MESTRADO & DOUTORADO & $\begin{array}{c}\text { LIVRE- } \\
\text { DOCÊNCIA }\end{array}$ \\
\hline Educação & 142 & 18 & - \\
\hline Educação ambiental & 41 & - & - \\
\hline Ecologia & 15 & 04 & - \\
\hline
\end{tabular}




\begin{tabular}{|c|c|c|c|}
\hline Saúde Pública & 09 & 06 & -1 \\
\hline $\begin{array}{c}\text { Comunicações e } \\
\text { Artes }\end{array}$ & 04 & - & - \\
\hline Psicologia & 05 & 02 & - \\
\hline $\begin{array}{c}\text { Desenvolvimento e } \\
\text { meio ambiente }\end{array}$ & 08 & 01 & - \\
\hline Ciências ambientais & 03 & - & - \\
\hline Engenharia & 03 & 03 & - \\
\hline Geociências & 03 & - & - \\
\hline Sociologia & - & 03 & - \\
\hline Serviço Social & 02 & - & - \\
\hline Geografia & 02 & 02 & - \\
\hline $\begin{array}{c}\text { Desenvolvimento } \\
\text { agricultura e } \\
\text { sociedade }\end{array}$ & - & - & - \\
\hline Ciências florestais & 02 & - & - \\
\hline $\begin{array}{c}\text { Saúde e meio } \\
\text { ambiente }\end{array}$ & 01 & - & - \\
\hline Tecnologia & 01 & - & - \\
\hline $\begin{array}{c}\text { Saneamento, meio } \\
\text { ambiente e recursos } \\
\text { hídricos }\end{array}$ & 01 & - & - \\
\hline Antropologia & 01 & - & - \\
\hline $\begin{array}{c}\text { Integração latino- } \\
\text { americana }\end{array}$ & 01 & - & - \\
\hline Filosofia & 01 & - & - \\
\hline Saúde mental & 01 & - & - \\
\hline TOTAL & 246 & - & - \\
\hline
\end{tabular}

\section{Características e fundamentos da educação ambiental brasileira}

Tendo sido realizado o levantamento das dissertações e teses seguindo as categorias estipuladas, procedeu-se a análise de conteúdo (BARDIN, 1998; SPINK, 1999; MIRIM, 1999), a partir dos seus títulos.

A metodologia da análise de conteúdo é definida como

um conjunto de técnicas de análise de comunicações visando, por de processos sistemáticos e objetivos a descrição de conteúdo de mensagens para obter indicadores (quantitativos ou não, permitindo a inferência de conhecimentos relativos às condições de produção e 
recepção (variáveis inferidas) dessas mensagens. (BARDIN, 1998, p. 47).

Em relação à análise de conteúdo de documentos, a autora observa que esta caracteriza-se pela "manipulação de mensagens (conteúdos e expressões deste conteúdo) visando evidenciar os indicadores que permitem inferir sobre uma realidade outra que aquela da mensagem” (BARDIN, 1998, p. 51).

Nos últimos anos, vários programas tecnológicos foram desenvolvidos visando a análise de conteúdo (TRIVELIN, 2003); no entanto, optamos pelo estilo do arqueólogo no qual o analista "trabalha sobre pistas" (traces): os "documentos" que ele pode encontrar ou provocar (suscitar). Mas essas pistas são a manifestação do estado, de dados, de fenômenos. Há alguma coisa a descobrir por meio e graças a eles. Como o etnólogo necessita da etnologia para interpretar suas descrições minuciosas, o analista se aproveita do tratamento da mensagem que ele manipula para inferir (deduzir de maneira lógica) conhecimentos sobre o emissor da mensagem ou seu contexto (BARDIN, 1998, p. 43). Consideramos as teses e dissertações como documentos de domínio público, que

refletem duas práticas discursivas: como gênero de circulação, como artefatos do sentido de tornar público e como conteúdo, em relação aquilo que está impresso em suas páginas (...) os documentos de domínio público, como registros, são documentos tornados públicos, sua intersubjetividade é produto da interação com um outro desconhecido, porém significativo e freqüentemente coletivo. (SPINK, 1999, p. 126).

\section{Segundo o mesmo autor:}

Os documentos de domínio público são produtos sociais tornados públicos. Eticamente estão abertos para análise por pertencerem ao espaço público, por terem sido tornados públicos de uma forma que permite a responsabilização. Podem refletir as transformações lentas em posições e posturas institucionais assumidas pelos aparelhos simbólicos que permeiam o dia-a-dia ou, no âmbito das redes sociais, pelos agrupamentos e coletivos que dão forma ao informar, refletindo o ir e vir de versões assumidas ou advogadas. (SPINK, 1999, p. 136). 
Baseada nessa linha de raciocínio e atendo-se à produção científica, Lia Yara Lima Mirim (1999, p. 156) observa que:

Um artigo científico publicado pode transformar os tipos de enunciados, e as várias posições que já constituem o campo (...)Para que uma operação seja bem sucedida, ela depende do número de atores na área, do caráter inédito do que está em jogo, da personalidade e da filiação institucional dos atores, das apostas e do estilo do artigo.

Essas observações da autora nos permitem e permitiram fazer analogias com a produção de teses e dissertações em educação ambiental e, conseqüentemente, com a análise de conteúdo, procurando decifrar e evidenciar as suas principais características e redes sociais de produção. Dessa forma, temos claro e concordamos que

a construção de um levantamento bibliográfico é um exemplo claro da natureza social da pesquisa. Um levantamento bibliográfico é permeado por inúmeras decisões, todas elas pautadas pelas vicissitudes do pesquisador. Assim, o resultado de um levantamento bibliográfico, tomado como discurso, constitui uma dentre as múltiplas versões possíveis sobre o tema pesquisado. A possibilidade da escolha está inevitavelmente envolvida no cotidiano de pesquisa, uma vez que as práticas discursivas em que uma pessoa poderia se engajar são numerosas e contraditórias. (MIRIM, op. cit., p. 181).

Com esse referencial teórico-metodológico, estabelecemos os seguintes itens:

- Temática ambiental;

- Características pedagógicas;

- Contexto teórico-metodológico;

- Características políticas.

\section{Temática ambiental}

A temática ambiental presente na produção brasileira é muito variada. Essa temática ampla e genérica é definida como "degradação ambiental", "crise ambiental", "problemas socioambientais", "alterações ambientais globais", etc. No entanto, é a análise da relação entre natureza e cultura a que predomina, 
estando presente em pelo menos 30 trabalhos, entre os quais se destacam os de Amorim (1997), Bellavilla (1994), Coutinho (1994), Flores (2000) e Neto (1999).

Entre as teses e dissertações, verifica-se também a busca pela fundamentação de caráter filosófico, como nas teses de Zancanaro (1999) e Matsushima (1992) e nas dissertações de Dalmas (1998), Jesus (1998) e Unger (1998).

Temas específicos relacionados com ecologia, unidades de conservação, lixo, saúde, recursos hídricos e bacias hidrográficas, ecossistemas e ocupação de espaço são os mais explicitados.

Tabela VII - Temas ambientais presentes nas teses e dissertações

\begin{tabular}{|c|c|c|c|}
\hline $\begin{array}{c}\text { TEMA } \\
\text { AMBIENTAL }\end{array}$ & MESTRADO & DOUTORADO & $\begin{array}{c}\text { LIVRE- } \\
\text { DOCENCIA }\end{array}$ \\
\hline Ecologia & 14 & 04 & - \\
\hline $\begin{array}{c}\text { Unidades de } \\
\text { conservação }\end{array}$ & 11 & 01 & - \\
\hline Lixo & 13 & - & - \\
\hline $\begin{array}{l}\text { Recursos hídricos } \\
\text { e bacias } \\
\text { hidrográficas }\end{array}$ & 01 & 09 & 01 \\
\hline Saúde & 11 & 01 & - \\
\hline Ecossistemas & 01 & 06 & - \\
\hline $\begin{array}{c}\text { Ocupação do } \\
\text { espaço }\end{array}$ & 06 & 01 & \\
\hline
\end{tabular}

Análises dos problemas socioambientais urbanos são realizadas nos trabalhos de Campos (2001), Dias (1998), Freitas (1997), Higuchi (1999), Pelicioni (1995), Rechineli (2000), Reigota (1990), Roveratti (2000), Santos (2001) e Souza (2000).

Temas polêmicos, como violência (ANDRADE, 2001), transgênicos (CAPORLÍNGUA, 2001) ou sexualidade (SOARES, 1999), foram encontrados em apenas uma dissertação.

Os dados quantitativos e os exemplos citados confirmam e reforçam a idéia da amplitude da temática ambiental e de sua presença em diversos programas de pós-graduação. 


\section{Características pedagógicas}

Subdividimos as características pedagógicas das teses e dissertações em educação ambiental em: relações com as disciplinas escolares; fundamentos teóricos; instituições escolares; metodologias de ensino; formação de professores; propostas curriculares; espaços de aprendizagem; processos de avaliação; estrutura de ensino; material didático; e grupos sociais.

Os dados quantitativos apontam, nas dissertações, uma predominância de estudos relacionados com as práticas pedagógicas cotidianas (42), com o ensino fundamental (19), com a escola pública (15), com o ensino de Ciências (13) e com a análise de propostas curriculares (11).

Nas teses, destacam-se os estudos que relacionam a educação ambiental com o ensino de Ciências, Biologia, Geografia, Ecologia e o enfoque na instituição escolar, desde as creches até os cursos de pós-graduação.

Entre as dissertações, encontramos quatro relacionadas com o ensino de Biologia, quatro com Geografia, três com Ecologia, três com Educação Artística. Não faltam também trabalhos relacionados com o ensino de Química, Literatura Infantil, Música, Matemática e Educação Sexual.

Em relação aos fundamentos teóricos, predominam estudos sobre o cotidiano escolar e outros que lembram a obra de Paulo Freire, pois se referem à "Pedagogia dialógica", "Pedagogia transformadora", "Educação popular", "Temas geradores" e "Conscientização" (PELICIONI, 2002; SOARES, 2002; MARTINELLI, 2001; MOREIRA, 2000).

As escolas públicas são as que têm contribuído com maior quantidade de estudos, nos seus diferentes níveis, com destaque para o ensino fundamental. No entanto, encontram-se trabalhos voltados para a escola particular, colégios de aplicação, escola rural e para cursos como o técnico agrícola, magistério e extensão rural.

Teses e dissertações voltadas para a análise da formação dos professores e de outros agentes educativos também foram produzidas (LUZ, 2001; ALMEIDA, 2000; BOTELHO, 1998).

A escola tem constituído o espaço pedagógico majoritário nas teses e dissertações, seguida das unidades de conservação. 
Encontramos ainda trabalhos relacionados com museus (ALMEIDA, 1995) e zoológicos (MERGULHÃO,1998).

Entre os estudos sobre materiais pedagógicos, predominam os relacionados a livros didáticos (ADVERSARI, 1995; AMORIM, 1997). Nesse item, encontram-se trabalhos relacionados com fotografia (GASTAL, 2002) e computadores (FERREIRA, 1999; MONTEIRO, 1999).

A educação ambiental está voltada para vários grupos sociais. No entanto, pelo menos 18 trabalhos priorizam os professores. Outros grupos sociais, como o dos estudantes, vêm logo em seguida, com pelo menos 15 teses e dissertações.

No nosso levantamento, encontramos, ademais, trabalhos relacionados com pesquisadores ambientais, jovens em situação de risco, profissionais do lixo, adolescentes, imigrantes alemães, mulheres trabalhadoras, portadores de deficiência, recursos humanos, pescadores, favelados, operários, classes populares, povos da floresta, comunidades indígenas e grupos de terceira idade.

\section{Contexto teórico-metodológico}

No conjunto da produção brasileira, há poucas referências explícitas ao contexto teórico-metodológico nos títulos das teses e dissertações.

Podemos identificar um predomínio de trabalhos que procuram analisar as percepções, signos, significados, representações, representações sociais, concepções e conceitos prévios de grupos específicos.

Ainda nessa perspectiva, mas sem explicitar os conceitos e, portanto, a matriz teórico-metodológico adotada, encontramos uma série de trabalhos que analisam as falas, perspectivas, valores, crenças, visões, pensamentos e opiniões de grupos sociais.

Assim, temos as correntes cognitivistas (cujos conceitos de percepção e concepções se sobressaem) e as voltadas para o estudo do imaginário, nas quais, além do estudo das representações, signos e significados, destacava-se o uso da Teoria das Representações Sociais (MOSCOVICI, 1978), retomada em pelo menos 8 dissertações (ANGONES, 2000; FIGUEIREDO, 2000; LEÃO, 
1996; OKAMURA, 1996; SILVA, 2000) e uma tese de doutorado (REIGOTA, 1990).

Entre os trabalhos cognitivistas, apenas um faz referência explícita ao sociocognitivismo de Vigotsky (SPAZZIANI, 1999).

A interdisciplinaridade é a referência teórica explicitada em pelo menos uma tese (DIAZ, 2001) e em 8 dissertações, entre elas: Assunção (1995), Cascino (1998), Piovesan (1998).

Além das concepções teóricas acima explicitadas, encontramos trabalhos relacionados com os estudos culturais, perspectiva de gênero, complexidade, teoria sistêmica, memória cultural, transdisciplinaridade, epistemologia, ecofeminismo, teoria literária, semiótica, etc. Entre os trabalhos que enfatizam a opção metodológica, temos um grande predomínio de estudos de caso (18 dissertações).

Entre as propostas metodológicas, encontramos, também, histórias de vida, análise de discursos, pesquisa-ação, pesquisa participante, modelagem semiquantitativa e estudos comparativos.

\section{Características Políticas}

As características políticas dos trabalhos em educação ambiental são pouco explicitadas nos títulos das teses e dissertações. No entanto, encontram-se referências à ideologia do desenvolvimento, estratégia do Banco Mundial, pensamento de esquerda, sociedade civil, transformação social, ideologia empresarial, poder, nacionalismo, utopias concretizáveis, classes populares e intervenção.

A contribuição da educação ambiental à participação e construção da cidadania está explicitada em pelo menos 2 teses e 10 dissertações.

A análise e sugestões de políticas públicas também se destacam, estando explicitadas em pelo menos 12 dissertações.

As experiências de desenvolvimento local estão presentes em pelo menos 10 dissertações.

Os estudos relacionados com a sociedade civil, movimentos sociais e ONGs estão explicitados em pelo menos 6 dissertações e 2 teses. 
As referências e os exemplos dados apontam para uma crescente análise dos aspectos políticos da educação ambiental, caracterizada, principalmente, para as políticas públicas, movimentos sociais e construção da cidadania.

\section{Que singularidade atribuir à educação ambiental?}

Isabelle Stengers faz essa questão acima em relação às ciências e argumenta que a atividade científica "integra uma forma de polêmica e rivalidade, promove um 'compromisso' que liga interesse, verdade e história” (STENGERS, 2002, p. 159).

Poderíamos utilizar o mesmo argumento da autora, que analisa principalmente as ciências modernas teórico-experimentais, para uma análise da singularidade da educação ambiental no contexto contemporâneo das atividades científicas?

Apoiados nos seus argumentos, podemos procurar traçar e identificar o processo pelo qual a educação ambiental brasileira tem se constituído como um campo de atividade científica da área educacional, mas não ficando restrita aos seus limites, dialogando e se fazendo presente em diversos outros espaços de produção de conhecimento, tais como: ecologia, saúde pública, sociologia, psicologia, filosofia, etc.

Stengers não nos oferece a resposta imediata; no entanto, o seu trabalho pode contribuir para a reflexão sobre o processo de visibilidade e legitimidade da educação ambiental nas universidades e institutos de pesquisa (STENGERS, 1993; 2002).

Usando os seus termos e com os dados que nossa pesquisa mostra, podemos dizer que a educação ambiental brasileira provoca "interesse" e rompeu o "muro de indiferença", podendo assim “existir” (STENGERS, 2002, p. 114/117).

Mas onde, afinal, se encontra a sua singularidade?

Ao longo deste artigo, procuramos exemplificar situações que mostram que a atividade científica da educação ambiental está profundamente relacionada com sujeitos que foram buscando e criando espaços para a produção de conhecimento nessa área.

Esses sujeitos, que foram aqui nominados, mas que não são os únicos, formam o "núcleo histórico", que pode ser analisado na 
perspectiva das "minorias ativas", conforme as define Moscovici (1996; 2003).

Diz o autor que "as minorias não são os únicos inovadores, porém, através da história, elas se mostraram, muitas vezes, como os principais agentes de inovação na arte, ciência, política e assim por diante" (MOSCOVICI, 2003, p. 349).

Mas quais são as inovações dessa minoria ativa, depois que conseguiu romper o muro de indiferença e provocar interesse, constituindo assim a sua singularidade?

É bastante conhecido o contexto histórico brasileiro e internacional sobre o surgimento da educação ambiental (PELICIONI, 2002). Quando os sujeitos do núcleo histórico, com ações no movimento social e em busca de fundamentação teórica, decidiram pesquisar, tiveram que buscar professores/as e departamentos que pudessem acolhê-los. Dessa forma, a produção de conhecimento está intimamente ligada às trajetórias dos sujeitos, relacionando "produção de saber e produção de existência" (STENGERS, 2002, p. 202).

Foram muitos os professores/as que acolheram essa demanda em departamentos tão diferenciados, passando da engenharia à comunicação, das geociências ao serviço social, da saúde mental às ciências florestais, da antropologia ao saneamento, mas se concentrando sobretudo na educação.

Esse movimento dos sujeitos precisa ser analisado em outros estudos para que se possa identificar todo o seu significado no processo de inovação ao mesmo tempo social, político e científico (MOSCOVICI, 1996; 2003) e no tocante às singularidades (STENGERS, op. cit.).

A cartografia da produção brasileira em educação ambiental também tem um significado digno de análise, pela sua concentração regional e pelas ausências.

Não são poucas as universidades brasileiras onde o muro da indiferença foi rompido; no entanto, essa possibilidade precisa ser ampliada principalmente nas universidades do norte do país.

A educação ambiental tende a se ampliar, saindo dos temas clássicos para abordar uma temática cada vez mais conflituosa e cujas representações e interesses são múltiplos e com forças políticas extremamente diferenciadas. Questões como as 
relacionadas aos transgênicos, à biodiversidade, à saúde mental nas metrópoles e aos saberes tradicionais e étnicos deverão estar presentes com maior freqüência em trabalhos futuros.

A produção de conhecimentos sobre essa temática, por meio da educação ambiental, permitirá que ações políticas e pedagógicas estejam pautadas em competência técnica mais sólida.

Se, como se tem afirmado, a educação ambiental é uma educação política (PELICIONI, 2000 e 2002; REIGOTA, 1990), cabe a esse movimento ampliar e deixar claro o seu compromisso político.

Portanto, a competência técnica está intimamente relacionada com o compromisso político, sendo esse voltado para a consolidação de uma sociedade democrática, livre, autônoma, justa e sustentável.

Se a educação ambiental brasileira conseguir ampliar a sua influência e presença, como uma atividade científica e política, a sua singularidade ficará melhor explicitada não só para nós, sujeitos, mas - o que é mais importante e fundamental - para a sociedade que financia e aguarda os resultados de nossas atividades.

A educação ambiental, assim definida, é herdeira do pensamento pedagógico crítico e propositivo iniciado por Anísio Teixeira, Paulo Freire, Darcy Ribeiro e tantos outros professores e professoras que não abandonam, em nome de uma competência técnica específica, o compromisso político de intervir e participar constantemente da transformação social. A sua singularidade é colocar a perspectiva ecológica em evidência.

A pretensão da educação ambiental em formar cidadãos e cidadãs críticos e participativos não é de transformá-los em ecologistas e/ou ambientalistas inseridos num partido ou num movimento, mas sim formar pessoas "em situação de exigir que os cientistas respondam às suas perguntas, se esforcem por tornar a 'informação' que possuem pertinente e utilizável, em suma, se dirijam a eles como a interlocutores de quem seu trabalho depende" (STENGERS, op. cit., p. 195).

A característica rizomática do estado da arte da educação ambiental fica evidente ao observarmos os lugares/espaços de produção. Tendo em vista que o rizoma implica a conexão entre heterogêneos (STENGERS, op. cit.; GALLO, 2003), resta saber 
como essa conexão se dá nas práticas pedagógicas cotidianas, no interior das escolas, universidades e outros espaços de aprendizagem.

Estará a educação ambiental, mediante as práticas cotidianas explicitadas nas teses e dissertações, alterando, modificando, fazendo a diferença no cotidiano escolar? Estarão essas práticas pedagógicas cotidianas fundamentando e exercitando o que num devir próximo poderá ser conhecido como perspectiva ecologista, do mesmo modo como em outros tempos se solidificaram e ganharam visibilidade e legitimidade as perspectivas anarquista, liberal, socialista e tecnicista de educação?

Para que possamos dar uma resposta mais clara $\mathrm{e}$ abrangente à questão inicial sobre a singularidade da educação ambiental, necessitamos responder essas questões intermediárias.

Nossa pesquisa levanta algumas questões que poderão ser respondidas com o acúmulo de estudos sobre o mesmo tema.

\section{Conclusão}

No momento em que iniciamos esta pesquisa, a educação ambiental já havia consolidado a sua legitimidade em muitos espaços políticos, sociais e acadêmicos.

Ao conclúi-la, nos surpreendemos com a quantidade e a diversidade temática abordada nas teses e dissertações defendidas em vários programas de pós-graduação, no Brasil e no exterior.

É oportuno observar que, no período analisado (19842002), a maior parte dessa produção foi defendida em programas de pós-graduação em educação (18 teses e 142 dissertações), num total de 1 tese de livre-docência, 40 teses e 246 dissertações.

Outros programas de pós-graduação, como os de Saúde Pública, Ecologia, Educação ambiental e multidisciplinares, também apresentam uma significativa produção.

O movimento da educação ambiental nas universidades brasileiras enfatiza a sua amplitude para além de uma área específica e a sua institucionalização como área de conhecimento.

Apesar de nossa pesquisa procurar ser a mais ampla possível, sabemos que a mesma encontra-se longe de ser conclusiva e que não esgotamos o assunto. Possivelmente, estamos apenas 
iniciando o processo de análise dos fundamentos políticos e pedagógicos da produção brasileira.

Acreditamos que este trabalho inicial será ampliado e aprofundado com a constituição de um banco de dados específico, que poderá auxiliar futuras pesquisas com base nos fundamentos e categorias aqui enunciados.

Gostaríamos de enfatizar que nossa pesquisa aponta para a necessidade de se ampliar, estimular e diversificar a pesquisa em educação ambiental nos Programas de Pós-graduação (em qualquer área). Aponta também para a necessidade de intensificar os intercâmbios internacionais nos quais os/as pesquisadores/as brasileiros/as possam dialogar com os seus pares e vivenciar outros contextos políticos, culturais, sociais, educacionais e ecológicos.

A difusão da produção brasileira deve ser também estimulada, para que os/as pesquisadores possam ampliar a sua participação e influência (inter)nacional na definição de políticas públicas para a educação ambiental, linhas de pesquisa e docência sobre o tema.

A consolidação, em 2004, do grupo de trabalho em educação ambiental na ANPEd (Associação Nacional de PósGraduação e Pesquisa em Educação), depois de um longo processo iniciado por pesquisadores e pesquisadoras da área em 1997, constitui um marco fundamental na visibilidade e legitimidade da produção científica. Espera-se também que com o GT em Educação Ambiental da ANPED se amplie (e se justifique) a influência de pesquisadores/as da área, junto aos programas de pós-graduação, nas agências financiadoras de pesquisa e nas instituições responsáveis pela elaboração e condução de políticas públicas pautadas em sólidos referenciais teóricos e metodológicos.

Essa produção científica (em muitos casos realizada com dinheiro público) é uma contribuição valiosa para o desenvolvimento da educação ambiental no Brasil e o será até o momento em que não seja mais necessário adjetivar a educação.

\section{Referências bibliográficas}

ADVERSARI, O.A. O enfoque da educação ambiental nos livros didáticos de primeiro e segundo graus. Mestrado em Ecologia, Universidade Guarulhos, Guarulhos, 1995. 
ALMEIDA. A.M. A relação do público com o Museu do Instituto Butantã: Análise da exposição " $\mathrm{Na}$ natureza não existem vilões". Mestrado em Comunicações e Artes, Universidade de São Paulo, São Paulo, 1995.

ALMEIDA, M.M. Plano de capacitação em educação ambiental formal para o município de Rancho Queimado, Santa Catarina. Mestrado em Engenharia Ambiental, Pontifícia Universidade Católica do Rio Grande do Sul, Porto Alegre, 2000.

AMORIM, M.A.L. A relação homem-mundo natural nos livros didáticos de ciência. Mestrado em Educação, Universidade Federal de Santa Maria, Santa Maria, 1997.

ANDRADE, A.L.C. Educação ambiental e construção da cidadania: Uma prática com classes populares. Mestrado em Educação, Universidade Federal do Rio de Janeiro, Rio de Janeiro, 2003.

ANGONESI, M.A.G. Educação ambiental e representações sociais: Diálogos, ações educativas e desafios com professores de séries iniciais. Mestrado em Educação, Universidade Federal de Santa Maria, Santa Maria, 2000.

ASSUNÇÃO, L. W. Educação ambiental como um processo interdisciplinar: uma experiência com a coleta de lixo na escola estadual Joaquim Saraiva. Mestrado em Educação, Universidade Federal de Uberlândia, Uberlândia, 1995.

BARCELOS, V. e NOAL, F.; REIGOTA, M. (Orgs.). Tendências da educação ambiental. Santa Cruz do Sul: EDUNISC, 2001, 2ª edição.

Ecologia, literatura e educação ambiental: a contribuição de Octávio Paz. Doutorado em Educação, Universidade Federal de Santa Catarina, Florianópolis, 2001.

BARDIN, L. L'analyse de contenu. Paris: PUF, 1998, 9ème édition.

BELLAVILLA, E.P. Educação ambiental: um imperativo da nova relação homem-natureza. Mestrado em Educação, Universidade Federal Fluminense, Niterói, 1994.

BERGMANN, H.M.B. As relações entre gênero e meio ambiente no processo de ocupação do espaço: Terra Vermelha - Vila Velha - ES. Mestrado em Educação, Universidade Federal do Espírito Santo, Vitória, 1996.

BOTELHO, J.M.L. A educação ambiental na formação do professor para o ensino fundamental em Porto Velho - RO. Mestrado em Educação, Universidade Federal do Rio de Janeiro, Rio de Janeiro, 1998. 
BRAUM, M.C. Do vale das matas nativas ao vale do progresso: um estudo sobre as representações de ambiente em comunidades de imigrantes alemães. Mestrado em Educação, Universidade Federal do Rio Grande do Sul, Porto Alegre, 1999.

CADEI, M. S. Uma perspectiva de construção da cidadania: Educação Ambiental no Curso de Formação de Professores. Mestrado em Educação, Universidade Estadual do Rio de Janeiro, Rio de Janeiro, 1995.

CAMPOS, A.C. Resíduos sólidos urbanos: educação ambiental e análise de comportamento de estudantes de escolas de Feira de Santana. Mestrado em Engenharia Civil, Universidade Federal do Rio Grande do Sul, 2001.

CAPORLÍNGUA, V.H. Alimentos transgênicos: análise da problemática jurídica através da ética e educação ambiental. Mestrado em Educação Ambiental, Fundação Universidade Rio Grande, Rio Grande, 2001.

CARVALHO, L.M. A temática ambiental e a escola de primeiro grau. Doutorado em Educação, Universidade de São Paulo, São Paulo, 1989.

CARVALHO, V. S. Educação Ambiental e desenvolvimento comunitário: desafios e perspectivas. Mestrado em Educação, Universidade Federal do Rio de Janeiro, Rio de Janeiro, 1997.

CASCINO, F. Princípios interdisciplinares para a construção de uma educação ambiental. Mestrado em Educação (Currículo), Pontifícia Universidade Católica de São Paulo, São Paulo, 1998.

CATUNDA, M. O canto do céu aberto e de mata fechada. Mestrado em Comunicação e Artes, Universidade de São Paulo, São Paulo, 1993.

O canto do céu aberto e de mata fechada. Cuiabá: ed. da Universidade Federal do Mato Grosso, 1994.

COUTINHO, M. Reflexões acerca da estrutura do conhecimento ecológico: representações da natureza e representações de sociedade. Doutorado em Sociologia. Universidade de São Paulo, São Paulo, 1994.

CURVELO, M.A. A presença do enfoque agro-ecológico em currículo técnico agrícola. Mestrado em Educação, Pontifícia Universidade Católica do Rio de Janeiro, Rio de Janeiro, 1998.

DALMAS, G. O conceito filosófico de ambiente e a reconstrução da sustentabilidade ética: uma contribuição à educação ambiental. Mestrado em Educação Ambiental, Fundação Universidade Rio Grande, Rio Grande, 1998. 
DE KETELE, J.M. e ROEGIERS, X. Méthodologie du recueil d'informations: Fondements dês méthodes d'observations, de questionnaires, d'interviews et d'études de documents, Bruxelles, De Boeck Université, 1996, 3 ème édition.

DIAS, G. Educação ambiental: princípios e práticas. $6^{a}$ edição. São Paulo: Gaia, 2002.

DIAS, G.F. Estudo sobre o metabolismo socioecossistêmico urbano da região de Taquatinga - DF e as alterações ambientais globais. Doutorado em Ecologia, Universidade de Brasília, Brasília, 1998.

DIAZ, R.P. Interdisciplinaridade e meio ambiente em cursos de pós-graduação no Brasil. Doutorado em Desenvolvimento, Agricultura e Sociedade. Universidade Federal Rural do Rio de Janeiro, Rio de Janeiro, 2001.

DRUMMOND, J.A. e SCHROEDER, A. Programas de Pós-graduação em Ciências Ambientais e similares no Brasil - uma listagem preliminar. Ambiente \& Sociedade, no2, p. 10-20, 1998.

FELIPPE, C. Capital social e familismo amoral. Mestrado em Antropologia, Universidade Federal Fluminense, Niterói, 2002.

FERREIRA, T. R. Complexidade e adequação pedagógica de um projeto ambiental via internet: o programa educ@r. Mestrado em Educação, Universidade Metodista de Piracicaba, Piracicaba, 1999.

FIGUEIREDO, L.A.V. O meio ambiente prejudicou a gente...: Políticas públicas e representações sociais de preservação e desenvolvimento; desvelando a pedagogia de um conflito no Vale do Ribeira (Iporanga - SP), Mestrado em Educação, Universidade Estadual de Campinas, Campinas, 2000.

FLORES, J.A.V. Natureza, cultura, objeto e arte: o ambiente em situação de fronteiras: um estudo para a educação ambiental. Mestrado em Educação Ambiental, Fundação Universidade Rio Grande, Rio Grande, 2000.

FRACALANZA, D.C. Crise ambiental e ensino de ecologia: o conflito na relação homem-mundo natural.. Doutorado em Educação, Universidade Estadual de Campinas, Campinas, 1992.

FREITAS, E.Y. A floresta amazônica na concepção de professores e alunos da $5^{\text {a }}$ série das escolas estaduais do município de Manaus. Mestrado em Biologia Tropical, INPA-Manaus, Manaus, 1997.

GALLO, S. Deleuze e a educação. Belo Horizonte: Autêntica, 2003. 
GARNIER, C. Contribution de la théorie des représentations sociales au champ de l'éducation relative à l'environment. Les dossiers des sciences de l'education, $\mathrm{n}^{\circ} 4$, p. 23-42, 2000.

GASTAL, A.L. Do olhar à reflexão: a vivência fotográfica em ecossistemas como proposta de educação ambiental. Mestrado em Educação Ambiental, Fundação Universidade Rio Grande, Rio Grande, 2002.

GOLDGRUB, R. Papéis no mundo: escritas do silêncio, silenciadas subterrâneas. Mestrado em Educação (Currículo), Pontifícia Universidade Católica de São Paulo, São Paulo, 1998.

GOMES, L. O serviço social e a questão ecológica: uma articulação a ser construída. Mestrado em Serviço Social, Pontifícia Universidade Católica de São Paulo, São Paulo, 1997.

GOMES, M.M.P.L. Environmental education as an approach to improve science teaching: a study of a group of science teachers in Niterói, Rio de Janeiro, Brazil. Mestrado em Educação, Universidade de Kansas, Kansas, 1984.

GOUGH, N. Repensar el sujeto: (de)construyendo la acción humana en la investigación en educación ambiental. Tópicos en educación ambiental, vol. 2, $\mathrm{n}^{\circ} 4,2000$.

GOYA, E.M.M. Deconstrucción de las representaciones sobre el medio ambiente y la educación ambiental. Tópicos en educación ambiental, vol.2, no 4,p.33-40, 2000a.

- Desvelando a história da educação ambiental em Sorocaba. Mestrado em Educação, Universidade de Sorocaba, Sorocaba, 2000.

GUATTARI, F. As três ecologias. Campinas: Papirus, 1991.

GUEVARA, G.A.U. A educação ambiental num órgão governamental: A FEEMA. Mestrado em Educação, Universidade Federal do Rio de Janeiro, Rio de Janeiro, 1994.

GUIMARÃES, L. B. O educativo nas ações e lutas e movimentos de defesa ambiental: Uma história de descontinuidade. Mestrado em Educação, Universidade Federal do Rio Grande do Sul, Porto Alegre, 1998.

HALBRITTER, L. Método ludo-artístico para o ensino de adolescentes hipossuficientes na faixa etária de 14 a 17 anos. Mestrado em Educação, Universidade Estácio de Sá, Rio de Janeiro, 2000. 
HIGUCHI, M.I.G. House, street, bairro and mata: ideas of place and space in an urban location in Brazil. Doutorado em Psicologia, Brunel University of West London, London, 1999.

JESUS, E.L. Sociodiversidade no Jaú: a ética de (com)viver. Mestrado em Educação Ambiental, Fundação Universidade Rio Grande, Rio Grande, 1998.

KLEIN, E.J. A abordagem das relações entre os componentes ambientais dos livros didáticos de $1^{\circ}$ grau. Mestrado em Educação, Universidade Federal do Rio de Janeiro, Rio de Janeiro, 1984.

LEÃO, V. F. A representação social da fauna: uma contribuição à educação ambiental. Mestrado em Educação, Universidade Federal Fluminense, Niterói, 1996.

LEHER, R. Da ideologia do desenvolvimento à ideologia da globalização como estratégia do Banco Mundial para 'alívio’ da pobreza. Doutorado em Educação, Universidade de São Paulo, São Paulo, 1998.

LIMOEIRO, R. Concepções socioculturais de uma comunidade favelada sobre o meio ambiente: subsídios para um programa educacional. Mestrado em Educação, Universidade Federal do Rio de Janeiro, Rio de Janeiro, 1991.

LUZ, G.O. Formação de formadores em educação ambiental. Doutorado em Meio Ambiente e Desenvolvimento, Universidade Federal do Paraná, Curitiba, 2001

MARTINELLI, N.R.B. Educação ambiental no cotidiano das escolas: teorias e realidade. Mestrado em Educação Ambiental, Fundação Universidade Rio Grande, Rio Grande, 2001.

MATSUSHIMA, K. Perspectiva arquetípica e holística em educação ambiental.. Doutorado em Psicologia, Universidade de São Paulo, São Paulo, 1992.

MEGID, N.J. (coord.). O ensino de ciências no Brasil: catálogo analítico de teses e dissertações 1972-1995. Campinas: Universidade Estadual de Campinas, 1998.

MENDES, E.G., et al. A produção discente da pós-graduação e áreas afins: análise crítica das teses e dissertações sobre educação especial. Anais da XXX Reunião Anual de Psicologia, Universidade de Brasília, outubro, p. 11-12, 2000.

MERGUlHÃO, M. C. Zoológico: uma sala de aula viva. Mestrado em Educação, Universidade de São Paulo, São Paulo, 1998. 
MIRIM, L.Y.L. "Garimpando sentidos em bases de dados". In: SPINK, M.J. (Org.). Práticas discursivas e produção de sentido. São Paulo: Cortez, p. 153-182, 1999.

MONTEIRO, A.F.B. A educação ambiental pela rede mundial de computadores. Mestrado em Educação, Universidade Braz Cubas, Mogi das Cruzes, 1999.

MOREIRA, M.K.W. A dimensão ambiental no currículo escolar através de temas geradores de ensino na escola rural da região de Coxipó do Ouro - Cuiabá - MT. Mestrado em Educação, Universidade Federal do Mato Grosso, Cuiabá, 2000.

MOREIRA, R.J. e ROCHA, P.E.D. Interdisciplinaridade na pós-graduação: notas de pesquisa. Redes - Revista do Mestrado e Doutorado em Desenvolvimento Regional. UNISC, v. 7, nº2, p. 9-45, 2002.

MOSCOVICI, S. Representações sociais: investigações em Psicologia Social. Petrópolis: Vozes, 2003. . Psychologie des minorités actives. Paris: PUF, 1996, 2ème édition. - A representação social da psicanálise. Rio de Janeiro: Zahar, 1978.

NETO, B.M. Ecologia e imaginário nos Cariris Velhos do Estado da Paraíba: Memória cultural e natureza no cerimonial da vida. Mestrado em Desenvolvimento e Meio Ambiente, Universidade Federal da Paraíba, João Pessoa, 1999.

NEVES, P.C.B. Educação ou adestramento ambiental? Mestrado em Ecologia. Universidade Federal de Santa Catarina, Florianópolis, 1993.

NOAL, F. O movimento ecologista no Rio Grande do Sul: uma abordagem histórico-social no período de 1970 a 1995. Mestrado em Desenvolvimento Regional, Universidade de Santa Cruz do Sul, Santa Cruz do Sul, 1999.

NOVICKI, V. Educação ambiental: produção discente dos Programas de Pósgraduação do Rio de Janeiro (1981-1996). Anais do I Encontro de Pesquisa em Educação Ambiental, Rio Claro, 29,30 e 31 de julho, Universidade de São Paulo, Universidade Estadual Paulista e Universidade Federal de São Carlos, 2001.

OKAMURA, C. As representações sociais de meio ambiente de professores de educação ambiental. Mestrado em Psicologia Social, Pontifícia Universidade Católica de São Paulo, São Paulo, 1996. 
PÁDUA, S.M. Conservation awareness through an environmental education school program at the Morro do Diabo State Park, São Paulo state, Brazil. Mestrado em Artes, Universidade da Flórida, Flórida, 1991.

PELICIONI, A.F. Educação ambiental: limites e possibilidades de uma ação transformadora. Doutorado em Saúde Pública, Universidade de São Paulo, São Paulo, 2002.

PELICIONI, M.C.F. Qualidade de vida das mulheres trabalhadoras das creches conveniadas do bairro Bela Vista do município de São Paulo. Doutorado em Saúde Pública, Universidade de São Paulo, São Paulo, 1995.

- Serviços de saúde: utilização e opinião dos usuários. Mestrado em Saúde Pública, Universidade de São Paulo, São Paulo, 1989.

PIOVESAN, E.J. A visão sistêmica do ensino com pesquisa, como paradigma para uma abordagem interdisciplinar na educação ambiental. Mestrado em Educação, Pontifícia Universidade Católica do Paraná, Curitiba, 1998.

POMPÉIA, S. Formação ambiental de agentes locais. Mestrado em Ciência Ambiental, Universidade de São Paulo, São Paulo, 1995.

PORTILHO, M.F. Profissionais do lixo no Rio de Janeiro. Mestrado em Ecologia Social, Universidade Federal do Rio de Janeiro, Rio de Janeiro, 1997.

RECHINELI, I. Mudas da cidade: inclusão pela educação e cidadania. Mestrado em Educação, Universidade de Sorocaba, Sorocaba, 2000.

REIGOTA, M. Educação ambiental no Brasil: fragmentos de sua história. In: BARCELOS, V.; NOAL, F. e REIGOTA, M. (Orgs). Tendências da educação ambiental brasileira. Santa Cruz do Sul: EDUNISC, 2001, $2^{a}$ edição, 07:17.

. Ecologia, elites e intelligentsia na América Latina: um estudo de suas representações sociais. São Paulo: Annablume, 1999.

- Les representations sociales de l'environnement et les pratiques pedagogiques quotidiennes des professeurs de sciences à São Paulo - Bresil. Doutorado em Educação. Louvain : Universite Catholique de Louvain, 1990.

ROCHA, I.M. Protected áreas and no-governamental organizations in partnerships for conservation: case studies from Brazil and recommendations for the future. Mestrado em Artes, Universidade da Flórida, Flórida, 1994.

ROVERATTI, D.S. Diagnósticos de projetos de educação ambiental em escolas públicas das áreas de proteção de mananciais da represa Billings. Doutorado em Saúde Pública, Universidade de São Paulo, São Paulo, 2000. 
SANTOS, E.C. Meio ambiente através das manifestações dos povos da floresta uma análise crítica do festival folclórico de Parintins. Doutorado em Educação, Universidade Federal do Mato Grosso, Cuiabá, 2001.

SANTOS, K.J.V. Saúde e educação ambiental em Vargem Grande Paulista. Mestrado em Saúde Pública, Universidade de São Paulo, São Paulo, 2001.

SAUVÉ, L. Para construir un patrimônio da investigación em educación ambiental. Tópicos en Educación Ambiental, v.2, nº 5, p. 51-69, 2000.

SERRÃO, M.A. Da lógica dicotomizante à busca de novos paradigmas: o discurso dos pesquisadores ambientais do Rio de Janeiro. Mestrado em Ecologia Social. Universidade Federal do Rio de Janeiro, Rio de Janeiro, 1995.

SERRÃO, S. A educação ambiental feita por organizações governamentais e não-governamentais na região de Campinas, Mestrado em Educação, Universidade Estadual de Campinas, Campinas, 1995.

SEVERINO, A.J. A relevância social e a consistência epistêmica da pesquisa em educação: alguns subsídios para se avaliar a pesquisa em educação ambiental". Educação: teoria e prática, vol. 9, no 16 e 17 p. 10-16, 2001.

SILVA R.L.F. A educação ambiental nos cursos de licenciatura do Estado de São Paulo: Análise dos planos de ensino e representações sociais dos(as) professores(as). Mestrado em Ecologia, Universidade Guarulhos, Guarulhos, 2000 .

SOARES, D.G.F. Educação ambiental na Vila do Ananin-PA: conscientizando e integrando comunidades nas estratégias de conservação na Amazônia Oriental. Mestrado em Psicologia, Universidade Federal do Pará, Belém, 2002.

SOARES, G.F. Sexualidade e gravidez indesejada: um estudo sobre a educação sexual e sua articulação com a questão ambiental. Mestrado em Educação Ambiental, Fundação Universidade Rio Grande, Rio Grande, 1999.

SOUZA, D.V. As águas e o lugar: a vida e o meu refúgio. Mestrado em Saúde Pública, Universidade de São Paulo, 2002.

SPAZZIANI, M.L. Ouvindo Vigotski...dialogando com crianças... possibilidade de uma nova prática pedagógica para o ensino da saúde na escola. Doutorado em Educação, Universidade Estadual de Campinas, Campinas, 1999.

SPINK, P. Análise de documentos de domínio público. In: SPINK, M.J. (Org.). Práticas discursivas e produção de sentido. São Paulo: Cortez, p. 123-152, 1999. 
Representações sociais: questionando o Estado da Arte. Psicologia e Sociedade, volume 8, $\mathrm{n}^{\circ}$. 02, 1986, p. 166-186.

STENGERS, I. A invenção das ciências modernas. São Paulo: Ed. 34, 2002.

La volonté de faire science: a propôs de la psychanalyse. Paris, Éditions Synthélabo/Delagrange, 1993.

TRAJBER, R. e MANZOCHI, L.H. (Orgs.). Avaliando a educação ambiental no Brasil: materiais impressos. São Paulo: Gaia, 1996.

TRIVELIN, B. Note pratique: une aide à l'analyse de contenu: le tableau excel, Recherches Sociologiques, Université Catholique de Louvain, vol. XXXIV, nº1, 2003, p. 135-147.

UNGER, M.N. Cosmos e polis: Fundamentos filosóficos do pensamento ecológico. Doutorado em Educação, Universidade Estadual de Campinas, Campinas, 1998.

VASCONCELLOS, H.S.R. (Coord.). A educação ambiental na universidade: um banco de dados. Educação, $n^{\circ}$ 51, Departamento de Educação, Pontifícia Universidade Católica do Rio de Janeiro, 1999.

ZANCANARO, L. O conceito de responsabilidade em Hans Jonas. Doutorado em Educação, Universidade Estadual de Campinas, Campinas, 1999. 
